\title{
Study on Pervious Concrete by Partial Replacement of Silica Fume and GGBS with Cement and Addition of Glass Fibers
}

\author{
V Venkatadurga Raju ${ }^{1}$ V Bhargavi ${ }^{2}$ | Y Priyanka ${ }^{3}$
}

${ }^{1}$ PG Scholar, Department of Civil Engineering, Visakha Technical Campus, Andhra Pradesh, India.

${ }^{2}$ Associate Professor, Department of Civil Engineering, Visakha Technical Campus, Andhra Pradesh, India.

${ }^{3}$ Associate Professor, Department of Civil Engineering, Visakha Technical Campus, Andhra Pradesh, India.

To Cite this Article

V Venkatadurga Raju, V Bhargavi and Y Priyanka, "Study on Pervious Concrete by Partial Replacement of Silica Fume and GGBS with Cement and Addition of Glass Fibers", International Journal for Modern Trends in Science and Technology, 6(8): $66-71,2020$.

Article Info

Received on 06-June-2020, Revised on 28-June-2020, Accepted on 25-July-2020, Published on 31-July-2020.

\section{ABSTRACT}

Pervious Concrete for the pavements proves to be an effective and along-term solution for the universal problem of abnormal decrease of ground water table. Pervious Concrete has a unique mix design and giving special properties to the concrete which makes the concrete porous, allowing water from precipitation and other sources to pass directly through, there by reducing run off volume and increasing ground water table. Inorder to reduce the damage being caused to the environment by the use of cement, inpervious concrete, cement is replaced with pozzolanic materials such as GGBS, silica fume sand to increase strength and durability, glass fibers in stipulated ratio are added to the concrete mixture. In this study, the mix designs such as M3O and PC3O are considered. The fine aggregate is replaced with coarseaggregate by different ratios like $0 \%, 5 \%, 10 \%, 15 \%$. by adding different pozzolanic matrals like GGBS, silicafume with glassfibers. To find the effectiveness of the use of pozzolancic and glassfibes, compressive strength conducted. The following Conclusions can be summarized by analyzing tests performed on PC specimens. A significant reduction of workability. And A progressive addition in compressive strength by increasing the percentage of fine aggregates and pozzolanic materials in mix. The conclusion of fine aggregate content in the specimen increases the density and increase the pozzolanic materials addition. And addition of silica fume and GGBS in the mixtures improve strength, compressive strength increases even after adding pozzolanic materials. Due to increase of fine aggregate content. For all replacement levels of $P C$ with other mixes goes on decreasing in strength when compared with parent grade ofM30. While comparing with PC with Pozzolanic materials, For 7 days there is a drastic change for same replacement, and for 28 days itshowssimilar trend for 25\% pozzolanic concrete and goes on decreasing for strength for compressive strength. For all replacement levels of $P C$ with pozzolanic goes on decreasing in strength when compared with parent grade of M30. Compressive strength slightly increased by adding glass fibers to the allmixes.

KEYWORDS: pervious concrete, GGBS, silica fume, glass fibers, Compressive strength, split tensilestrength. 


\section{INTRODUCTION}

Concrete is a mixture of paste and aggregates, or rocks. The paste, composed of Portland cement and water, coats the surface of the fine (small) and coarse (larger) aggregates. So, concrete is the favorite choice as a construction material among civil engineers around the globe for decades. It is preferred for its better performance, longer life and low maintenance cost. Concrete is the most widely used construction material all over the world. It is difficult to find out alternate material for construction which is as suitable as that of such material form durability and economic point of view. The quantity of the water plays an important role in the preparation of concrete.Impurities in water may interfere the setting of the cement and may adversely affect the strength properties. The chemical constituents present in water may participate in the chemical reactions and thus affect the setting, hardening and strength development of mixture. The IS: 456-2000 code stipulates the water quality standards for mixing and curing. In some arid areas, local drinking water is impure and may contain an excessive amount of salts due to contamination by industrial wastes. When chloride does not exceed $500 \mathrm{ppm}$, or SO3 does not exceed 1000 PPM, the water is harmless, but water with even higher salt contents has been used Satisfactorily (Building researchstation 1956).

Pervious concrete pavements (PCP) are permeable pavement structures, simultaneously serving storm water management and bearing pedestrian/traffic loads, depending on the application. In this pavement system, a 150-300 $\mathrm{mm}$ pervious concrete (PC) layer with a high air void content is placed on a highly voided stone bed as the base layer, to allow for a rapid infiltration of runoff through the pavement system rather than allowing it to pond or run on the surface. For sidewalks, reduced icing and therefore pedestrian slipping, and for parking lots/bike trails and light traffic streets, reduced hydroplaning and wet weather accidents are among the additional expected outcomes of using PCP. PC's prominent characteristic is the high content of hardened air void, typically ranging between 15 and 25 percent of the total volume. Porosity is an essential property of $\mathrm{PC}$, impacting its hydraulic, mechanical and durability characteristics, and is highly dependent on the mixture design parameters and the method of compaction. PC mixture design is based on limiting the coarse aggregate grade to single-sized or grade 9.5-19 $\mathrm{mm}$, and either completely removing or using a minimal amount of fine aggregate for addedstrength.

\section{LITERATURE REVIEW}

Anush et al. ${ }^{11}$ In the last few years, the use of pervious concrete as a pavement material in low-volume road applications has gained importance due to its positive environmental aspects. This paper reviews the developments and state-of-the-art pertinent to pervious concrete research and practices. The investigations on mechanical-hydrological-durability properties of pervious concrete performed in various studies have been reviewed. The storm water purification efficiency of pervious concrete has been documented. The field investigations of few test sections and in-service pervious concrete pavements have been discussed. A review has been made on rehabilitation techniques to increase the hydraulic efficiency of pervious concrete pavements. A note has been mentioned on the life cycle cost analysis of pervious concrete. Due toanincreased use of pervious concrete in the pavement industry due to its multitudinous benefits, there exists an expansive scope for further research to understand the material better, which will make it a promising sustainable roadway material infuture.

B. Radha Kiranmaye et al. [2]Conventional Portland cement Concrete is commonly used for pavement construction. The impervious nature of the concrete pavements contributes to the increased water runoff into the drainage system, over-burdening the infrastructure and causing excessive flooding in built-up areas. Pervious concrete is a special type of concrete with a high porosity used for concrete pavement applications that allows water from precipitation and other sources to pass directly through, thereby reducing the runoff from a site and allowing ground water recharge. Theglass fiber can be the effective material to improve the properties of the pervious concrete. It will explore the use of glass fiber which is environmentally detrimental. The presence of glass fiber with cement content strengthens the concrete in greater extent. In this paper, glass fiber is used as partial replacement of cement in volume fraction of $1.5 \%$. Pervious concrete with little or no fine aggregate in various proportions is used. The 
study evaluates the effect of fine aggregate in varying fraction of $0 \%, 10 \%$ and $20 \%$ with coarse aggregate. The tests to be carried out to analyze the properties of pervious concrete are void ratio, compressive strength, flexural strength, split tensile strength and permeability test with varying fraction of fineaggregate.

B.V.R.Murthy, G.Rajeswari[3]Pervious Concrete Is A ConcreteContaining Little Or No Fine Aggregate Provides Direct Drainage Of Rainwater, Helps To Recharge Groundwater In Pavement Applications. The Objective Of This Work Is To Improve Compressive Strength At Which The Strength Achieves Better Permeability. The Design Mix Is Prepared For M25 Consisting Of 53 Grade Cement, Two Different Sizes Of Coarse Aggregate WhichArePassingThrough25mmI.SSieveSizeAndR etainedOn $16 \mathrm{mmI} . \mathrm{S}$ Sieve Size As S1 And Aggregates Passing Through $10 \mathrm{Mm}$ And Retained On $6 \mathrm{~mm}$ Named As S2 Were Taken For This Work River Sand And Robo Sand Were Selected As Fine Aggregate And W/C Ratio Maintained As 0.35 In All The Cases. The Design Mix Is Developed With Constant Percentage Of Coarse Aggregate And Altering The Proportions Of Coarse Aggregate With Simultaneous Addition Of Percentages Of River Sand And Robo Sand In The Concrete. From The Experimental Results It Is Found That The Compressive Strength And Permeability Is Satisfactory At Adding Of 5\% Robo Sand As A Fine Aggregate And Combination Of $80 \%$ S1 And 20\% S2 As Coarse Aggregate In The PerviousConcrete.

Dang Hanh Nguyen et al. ${ }^{[4]}$ As a new material type for pavement, pervious concrete should be designed to maintain both porosity and the structural strength. The actual mix proportions for pervious concrete depend on the application, the mechanical properties required and the materials used. Actually, the mix proportions of pervious concrete were determined for locally available materials based frequently on trial batching and experience.

Anotheranalyticalmethodshouldbedevelopedtofacil itatetheconcreteproducers. Based on the assumption that the cement paste only plays a role of coating, it does not fulfill the void among the grains of gravel; this paper focuses on one modified method for the design of the pervious concrete. The volume cement paste is divided by the surface area of the aggregates to determine the thickness of the excess paste. A scaling factor has been defined to evenly distribute the cement paste toward the size of gravel. Moreover, a binder drainage test is proposed to determine the critical $\mathrm{w} / \mathrm{c}$ ratio towards to prevent the flow of cement paste to the lower layers of concrete under the action of vibration or compaction. The pervious concrete has been formulated according to this method to validate it. The mechanical and hydraulic tests are performed to characterize the pervious concrete. The obtained pervious concrete presents a large sufficient permeability ( $\left.1 \mathrm{~mm} \quad \mathrm{~s} \_1\right)$ for draining rainwater and good mechanical resistance $(\mathrm{Rc}=$ 28.6 $\mathrm{MPa}$ ) with regard to typical pervious concrete applications such as parking lots, walkways and low-traffic roadways. In addition, the mechanical strength of pervious concrete in this research is found higher than that generally reported by other authors. The results indicate that the theoretical mix design method is a successful theory for an optimizing composition of pervious concrete.

\section{LutfurAkand, Mijia Yang, Xinnan Wang [5]Fiber} reinforcement delays the crack generation and enhances the strength of the host matrix. However, the bonding mechanism between fiber and concrete matrix is controversial in literature and needs better explanation. Due to surface smoothness and inert chemical nature of commercially available fibers, several mechanical and chemical treatment techniques have been studied by researchers to increase the fiber-matrix bonding properties. The use of fibers in pervious concrete is even more challenging due to high porosity and insufficient fiber-matrix bonding interface. This study discusses the effect of chemical treatment on short polypropylene fibers and its uses in pervious concrete as reinforcement. The change in fiber surface due to the treatment is determined through fiber wettability test and Atomic Force Microscopy (AFM). Changes on the tensile strength of fibers by the treatment methods are also tabulated. Single fiber pullout tests are conducted to study the effect of the treatment type on fiber-cement interface properties. Treated fibers are then put into pervious concrete matrix for compressive and flexural strength tests.Chemicaltreatmentsarefoundtoimprovethesu rfaceroughnessandcement matrix interface properties, as well as to enhance the overall strength of the fiber reinforced pervious concrete. 


\section{Materials}

\section{EXPERIMENTAL WORK}

\section{Binders}

Cement:-

Cement is a fine, grey powder. It is mixed with water and materials such as sand, gravel crushed stone to make a concrete. The ordinary cement contains two basic ingredients namely argillaceous and calcareous. In argillaceous materials, clay predominates and in calcareous materials calcium carbonate predominates. Ordinary Portland cement of grade - 53 (KCP cement) conforming to Indian standards (IS: 12269-1987) has been used in the present study.

\section{GGBS:-}

To produce GGBS, this granulated blast furnace slag is dried and ground to a fineness similar to that of Portland cement. GGBS is normally used in combination with Portland cement. The GGBS and cement are added into the concrete mixer as separate constituents. Where appropriate, the ratio of GGBS to cement can be varied according to the technical requirements for any particular application.

\section{Silica fume:-}

Silica fume is a byproduct of producing silicon metal or ferrosilicon alloys. One of the most beneficial uses for silica fume is in concrete. Because of its chemical and physical properties, it is a very reactive pozzolan. Concrete containing silica fume can have very high strength and can be very durable

Physical properties of fly ash \& GGBS and silica

\begin{tabular}{|c|c|c|c|c|c|}
\hline \multirow{2}{*}{$\begin{array}{r}\text { S. } \\
\text { No }\end{array}$} & \multirow{2}{*}{ IS Code } & \multirow{2}{*}{$\begin{array}{c}\text { Tests } \\
\text { performed }\end{array}$} & \multicolumn{3}{|c|}{ Results } \\
\hline & & & $\begin{array}{l}\text { Ceme } \\
\text { nt }\end{array}$ & $\begin{array}{l}\text { GG } \\
\text { BS }\end{array}$ & $\begin{array}{l}\text { Sili } \\
\text { ca } \\
\text { fume }\end{array}$ \\
\hline 1 & $\begin{array}{c}\text { IS } \\
12089: 1987\end{array}$ & $\begin{array}{l}\text { Specific } \\
\text { gravity }\end{array}$ & 3.13 & $\begin{array}{l}2.8 \\
2\end{array}$ & 2.63 \\
\hline 2 & $\begin{array}{c}\text { IS } \\
12089: 1987\end{array}$ & Fineness & $7.2 \%$ & $7 \%$ & $14 \%$ \\
\hline
\end{tabular}

\section{Fine and Coarse aggregate}

Fine aggregate used in this study was locally available river sand of Zone II compliing to IS 383:1970. The specific gravity, water absorption and fineness modulus of fine aggregate used was $2.55,0.806 \%$ and 2.58 .

Locally procured coarse aggregate from local quarry was used in this investigation. The specific gravity, Bulk density and Water absorption used was $2.9,1738 \mathrm{~kg} / \mathrm{m}^{3}$ (compacted), $1512 \mathrm{~kg} / \mathrm{m}^{3}$ (loosely packed) and $0.502 \%$.

\section{Water}

Water is a key ingredient in the manufacture of concrete. And in this investigation water participates in the chemical reaction with $\mathrm{NaOH}$ pellets. Since it helps to the strength giving binder gel, the quantity and quality of water are required to be looked into very carefully.

\section{Super Plasticizer}

To improve the workability of the silica/RHA based geopolymer concrete, conplast SP 430 super plasticizer which is obtained from FOSROC Constructive Solution Company. And also it served as a high range water reducer. The colour of the conplast is brown liquid and dosage of conplast added as $3 \%$ by weight of binder material.

\section{Glass fibre}

Glass fibre is a recent introduction in making fibre concrete. Fig. 5 shows glass fibre reinforced concrete (GFRC) much like you would find in fibreglass insulation, to reinforce the concrete. The glass fibre helps insulate the concrete in addition to making it stronger. Glass fibre also helps prevent the concrete from cracking over time due to mechanical or thermal stress. In addition, the glass fibre does not interfere with radio signals like the steel fibre reinforcement sdoes.

\section{Test details}

\section{Compressive Strength Test}

Compressive strength of hardened concrete is the most important of all the properties. The compressive strength test was carried out using 200 tonnes CTM. Testing procedure followed is as per IS 516:1959 [8].

\section{RESULTS AND DISCUSSIONS}

Compressive Strength Of Pervious Concrete; Various Pecetage Replacements of Cement With Other Cementatious Material.

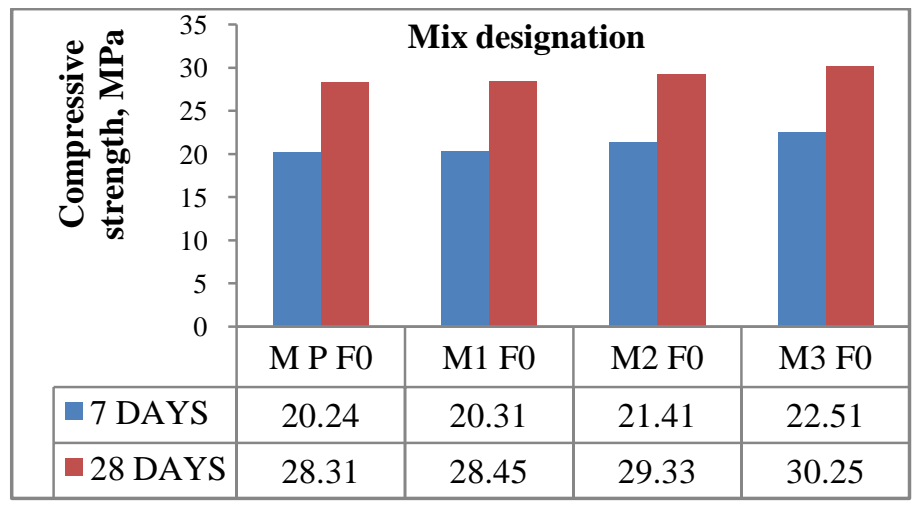


Compressive Strength Of Pervious Concrete; Various Pecetage Replacements of Cement With Other Cementatious Material And Different Percenatge Of Fine Aggregate And Addition With Glass Fibers

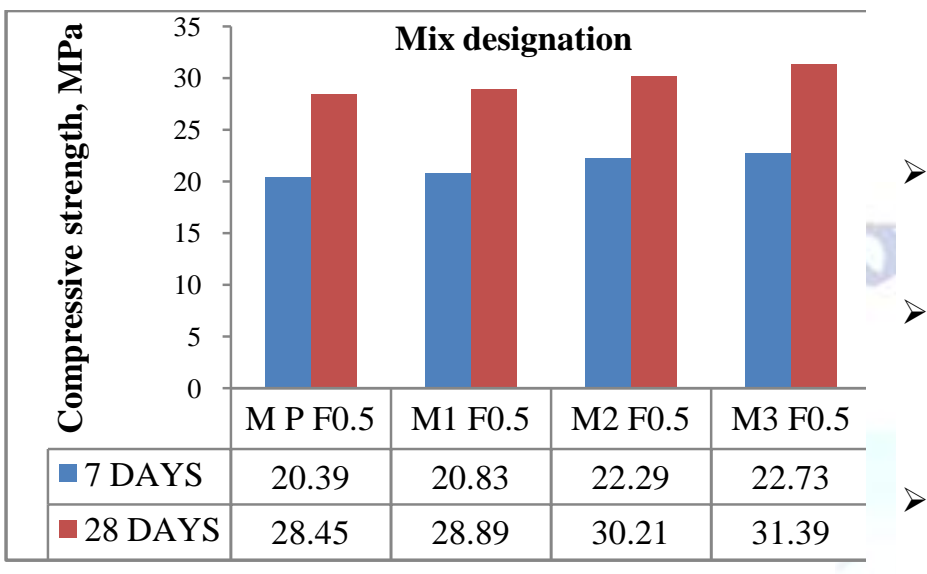

Compressive Strength Of Pervious Concrete; Various Pecetage Replacements Of Cement With Other Cementatious Material And Different Percenatge Of Fine Aggregate And Addition With Glass Fibers.

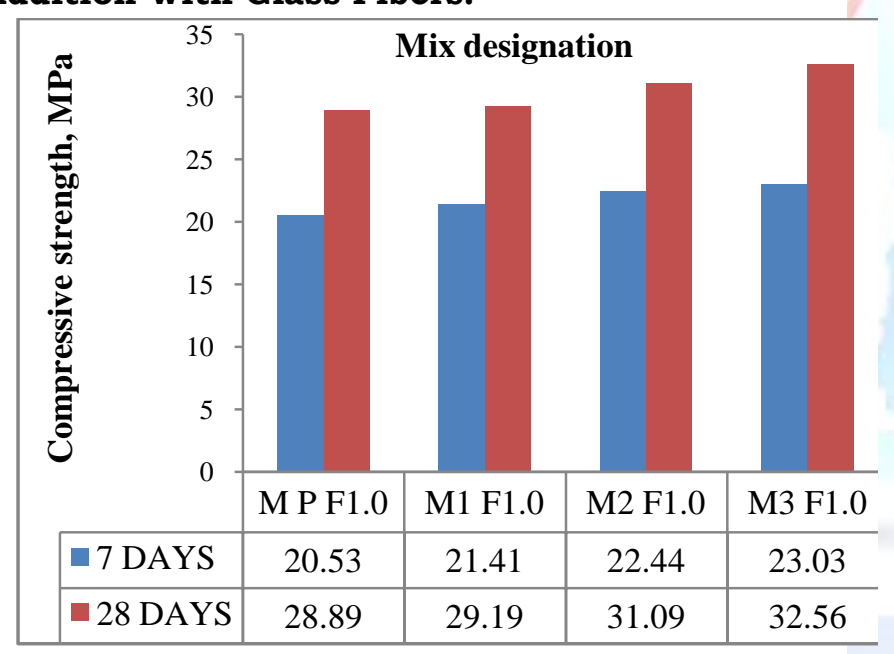

Compressive Strength Of Pervious Concrete; Various Pecetage Replacements Of Cement With Other Cementatious Material And Different Percenatge Of Fine Aggregate And Addition With Glass Fibers

\begin{tabular}{|c|c|c|c|c|c|}
\hline \multirow{4}{*}{ 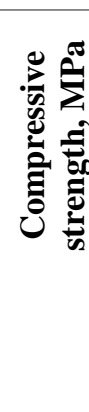 } & $\begin{array}{l}35 \\
30\end{array}$ & \multicolumn{3}{|c|}{ Mix designation } & \\
\hline & 15 & & & & \\
\hline & & & & & \\
\hline & 0 & M P F1.5 & M1 F1.5 & M2 F1.5 & M3 F1.5 \\
\hline$\square 7$ & YS & 20.68 & 21.56 & 22.59 & 23.32 \\
\hline$=28$ & AYS & 29.04 & 29.48 & 31.53 & 32.85 \\
\hline
\end{tabular}

\section{v. CONCLUSIONS}

Based on results and discussions following conclusions were made.

$>$ A significant reduction of workability.

$>$ A progressive addition in both split tensile and compressive strength by increasing the percentage of fine aggregates and pozzolanic materials in mix.

$>$ The inclusion of fine aggregate content in the specimen increases the density and increase the pozzolanic materials addition.

$>$ The addition of fly ash and silica fume and GGBS in the mixtures enhances the split tensile strength and compressive strength performance of the concrete,

The addition of Fly ash and silica fume and GGBS in the mixtures improve strength.

The split tensile strength and compressive strength increases even after adding pozzolanic materials. Due to increase of fine aggregate content. For all replacement levels of PC with other mixes goes on decreasing in strength when compared with parent grade ofM30.

\section{REFERENCES}

[1] Pervious concrete as a sustainable pavement material Researchfindings and future prospects: A state-of-the-art review Anush K. Chandrappa, Krishna PrapoornaBiligiri

[2] D. Cree, M. Green, A. Noumowe, Residual strength of concrete containing recycled materials after exposure to fire: a review, Constr. Build. Mater. 44 (2013) 208-223 (Elsevier).

[3] J. Yang, G. Jiang, Experimental study on properties of pervious concrete pavement materials, Cem. Concr. Res. 33 (2002) 381-386 (Elsevier).

[4] L.M. Haselbach, S. Valavala, F. Montes, Permeability predictions for sandclogged Portland cement pervious concrete pavement systems, J. Environ. Manage. 81 (2005) 42-49 (Elsevier).

[5] A. Volder, T. Watson, B. Viswanathan, Potential use of pervious concrete for maintaining existing mature trees during and after urban development, Urban For. Urban Greening 8 (2009) 249-256 (Elsevier).

[6] H. Takebayashi, M. Moriyama, Study on surface heat budget of various pavements for urban heat island mitigation, Adv. Mater. Sci. Eng. 42 (2012) 2971-2979 (Hindawi Publishing Corporation).

[7] K. C' osic', L. Korat, V. Ducman, I. Netinger, Influence of aggregate type and size on properties of pervious concrete, Constr. Build. Mater. 78 (2015) 69-76.

[8] A. Ibrahim, E. Mahmoud, M. Yamin, V.C. Patibandla, Experimental study on Portland cement pervious concrete mechanical and hydrological properties, Constr. Build. Mater. 50 (2014) 524-529.

[9] T.C. Fu, W. Yeih, J.J. Chang, R. Huang, The influence of aggregate size and binder material on the properties of pervious concrete, Adv. Mater. Sci. Eng. (2014)

[10] B. Rehder, K. Banh, N. Neithalath, Fracture behavior of pervious concretes: The effects of pore structure and fibers, Eng. Fract. Mech. 118 (2014) 1-16. 
[11] J.T. Kevern, D. Biddle, Q. Cao, Effects of macrosynthetic fibers on pervious concrete properties, J. Mater. Civ. Eng. 27 (9) (2014) 06014031.

[12] Q. Dong, H. Wu, B. Huang, X. Shu, K. Wang, Investigation into laboratory abrasion test methods for pervious concrete, J. Mater. Civ. Eng. 25 (7) (2012) 886-892.

[13] Yu Chen,KejinWang,Xuhao Wang \&Wenfang Zhou. (2013). Strength, fracture and fatigue of pervious concrete. Construction and Building Materials, 42, 97-104.

[14] M. Aamer Rafique Bhutta , K. Tsuruta \& J. Mirza. (2012). Evaluation of high-performance porous concrete properties. Construction and Building Materials , 31, 6773.

[15] G.Girish\&R.Manjunath Rao. (2011). A step towards mix proportioning guidelines for pervious concrete International Journal of Earth Sciences and Engineering, 4, $768-771$.

[16] Milani S. Sumanasooriya\& Narayanan Neithalath. (2011). Pore structure features of pervious concretes proportioned for desired porosities and their performance prediction. Cement \& Concrete Composites, 33, 778-787.

[17] Xiang Shu , Baoshan Huang, Hao Wu, Qiao Dong \& Edwin G. Burdette. (2011). Performance comparison of laboratory and field produced pervious concrete mixtures. Construction and Building Materials, 25 ,3187 3192.

[18] C. Lian, Y. Zhuge\& S. Beecham. (2011). The relationship between porosity and strength for porous concrete. Construction and Building Materials, 25 , 42944298.

[19] An Cheng, Hui-Mi Hsu, Sao-Jeng Chao \& Kae-Long Lin. (2011). Experimental Study on Properties of Pervious Concrete Made with Recycled Aggregate. Internal Journal of Pavement Research and Technology , 4 ,N0.2,104-110.

[20] Bradley J. Putman \& Andrew I. Neptune. (2011). Comparison of test specimen preparation techniques for pervious concrete pavements. Construction and Building Materials, 25, 34803485.

[21] H.K. Kim \& H.K. Lee. (2010) . Influence of cement flow and aggregate type on the mechanical and acoustic. Applied Acoustics ,71,607 615 .

[22] Narayanan Neithalath, Milani S. Sumanasooriya\& Omkar Deo. (2010) . Characterizing pore volume, sizes, and connectivity in pervious concretes for permeability prediction. Materials Characterization , 61, 802813.

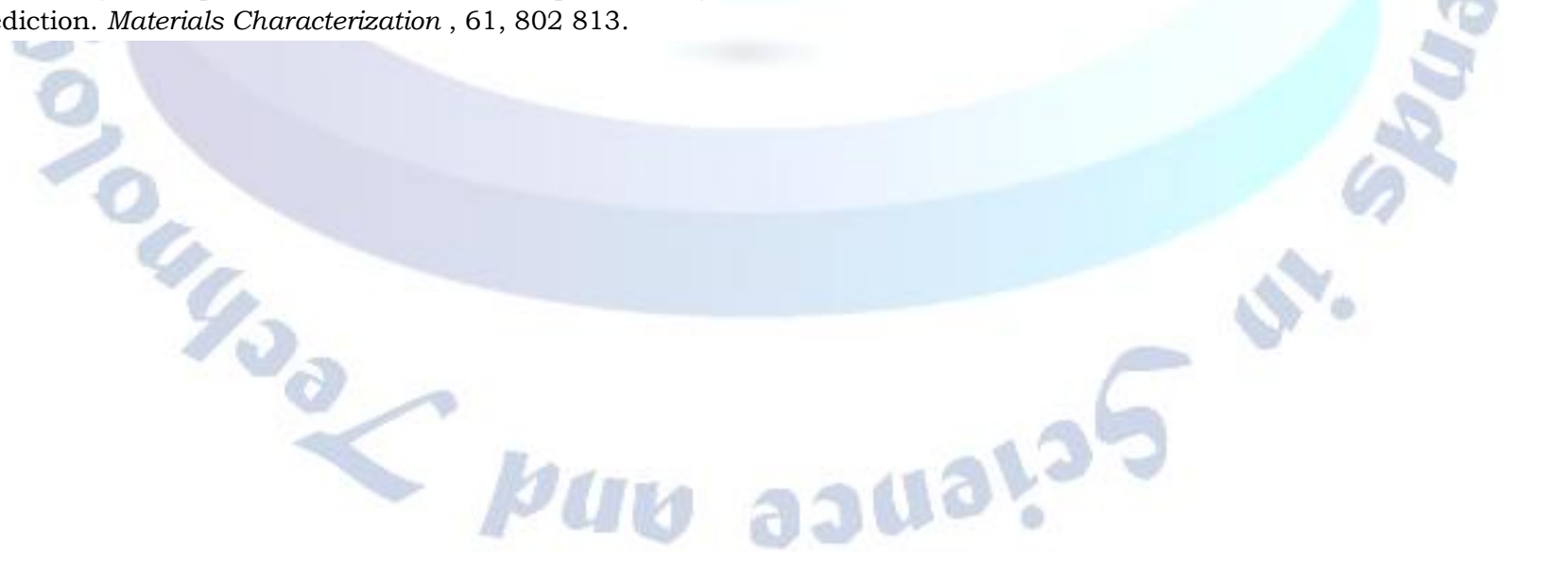

